This is the author's penultimate, peer-reviewed, post-print manuscript as accepted for publication. The publisher-formatted PDF may be available through the journal web site or, your college and university library.

\title{
Technological concerns for library managers
}

Mark Stover

\section{Manuscript Citation:}

The following (APA) citation may be used to reference this manuscript:

Stover, M. (2000). Technological concerns for library managers. Retrieved from http://scholarworks.csun.edu

\section{Version of Record Information:}

Citation: Stover, M. (2000). Technological concerns for library managers. Library Management, 21(9), 472-483.

Copyright: Copyright (C) Taylor \& Francis Group, LLC

(DOI):

URL: http://www.emeraldinsight.com/journals.htm?issn=01435124\&volume=21\&issue=9

This item was retrieved from CSUN ScholarWorks, the open-access, institutional repository of California State University, Northridge. http://scholarworks.csun.edu 


\title{
TECHNOLOGICAL CONCERNS FOR LIBRARY MANAGERS
}

\author{
By Mark Stover
}

\section{KEYWORDS}

\section{Libraries; Management; Information Technology.}

\begin{abstract}
Library managers face a variety of questions and concerns on a daily basis related to information technology. These include the relative merits of interpersonal and communication skills as compared with technical abilities; the organizational structure that should be utilized in the distribution of computing resources; the policies that need to be created (or enforced) in relation to the personal use of business computers; issues surrounding computer usage problems (such as carpal tunnel syndrome) that pose potential threats to staff productivity; and the library manager's pursuit of the "cutting edge" of technology. This study uses qualitative survey data to find patterns and themes among librarians in regard to their attitudes toward managing technology and technological change. It includes a selection of categorized survey responses, interpretation of the data by the author, and suggestions for further research.
\end{abstract}




\section{INTRODUCTION}

How are librarians handling technological change, whether on a personal level or on an organizational level? What sort of skills do managers need in today's information-based organizations? These are the kinds of "big" questions that librarians need to find answers to as we enter a new millennium of challenges and change. This article, based on qualitative research, will attempt to provide preliminary answers to these questions and sketch out themes and patterns for our changing profession.

The professional literature contains many articles and books that address issues related to library management and information technology (Farrow, 1997; Foster and Bell, 1998;

Hudson, 1999; Lancaster and Sandore, 1997; Lowry, 1993; Martin, 1999). Some authors, such as Donald Riggs, take an optimistic stance in this realm. In a recent editorial Riggs (1999, p. 513) proclaims that "[n]early all components of library management have been enhanced by modern technology" and that "[e]volving technology is making the library manager's job easier." Others, such as Michael Gorman (1997), opine that caution and moderation are the watchwords when managing libraries and technology. Yet, while an abundance of literature exists on this topic, and while a variety of perspectives have been championed by library managers across the spectrum, few if any studies have provided the actual "voices" of librarians discussing the issues that arise when library management intersects with information technology. This study seeks to accomplish the following: to categorize and summarize the comments of librarians in reaction to questions about library management and technology; to discover themes and patterns in this area; and to provide a basis for future quantitative research in this area. 


\section{METHODOLOGY}

In June 1998 I published a questionnaire on my Web site designed to elicit qualitative data about information professionals and technology.[1] I posted the address of the Web site to various library and technology listservs, and over a period of one month received 41 responses to the questionnaire. This article focuses on five questions in the survey that deal with managing technology in libraries (see Appendix).

The qualitative methodological approach can be a useful research method for gathering information. It does not require a large population of respondents (such as is necessitated by most quantitative, statistically-based research) to be methodologically sound. It allows the researcher to collect responses from a questionnaire in the respondents' own words, and it provides a way to see patterns and themes on various topics that otherwise might not be noticeable. The colorful stories that are generated by qualitative research can in many ways be more enlightening to the reader than the charts, graphs, and complex statistical analyses of sterile numbers that are often found in quantitative research studies.

The qualitative method uses open-ended questions, which often elicit lengthy answers filled with numerous details and examples. While the volume of information can be quite challenging for the researcher, the data generated by open-ended questions frequently develop into a rich repository for thematic analysis. 
The respondents to this survey were anonymous and did not provide demographic identification data such as gender, age, or place of employment. Anonymity ensures confidentiality and encourages candor, but it also limits our knowledge of the job level of the respondents. For example, we do not know whether the respondents are systems librarians or systems managers, or perhaps neither. While this knowledge is not crucial to the successful explication of qualitative surveys, it does allow for a more precise analysis of the data.

Although the questionnaire originated in the United States, the international nature of Internet listservs makes it likely that at least some of the respondents live and work elsewhere. Thus, despite potential national bias by the author and the respondents (most of whom we may safely assume work in the United States), the data and its interpretations should be viewed as having some international implications.

\section{RESEARCH FINDINGS}

\section{Managerial Skill Sets}

What do you think is more important for a manager of computer resources: technology skills or interpersonal skills? Why? 
Somewhat less than half of the respondents $(44 \%, n=18)$ answered that interpersonal skills were more important. As one person said, "Technicians need to have the nuts and bolts down, but managers interface between professionals and executive management" and thus need to have good communication skills. Another wrote, "One needs team efforts and one needs adroit political skills in marshalling resources and support. I suspect it is interpersonal skills, ultimately, in any environment." A third stated, "By and large, the ability to articulate the technology in ways that other professionals can understand is far more valuable than a strong technical knowledge....at least in library settings."

Some of the respondents believed that highly technical people generally have poor interpersonal skills, and need to have a interpersonally proficient manager create a buffer between them and the rest of the staff. One person stated, "In my personal experience, technicians seem to lack social skills, do not listen, go ahead and do what they think is right, and then wonder why people are frustrated with them." This person added that "being a good listener is critical," and that technical staff do not seem to have good listening skills.

Another reason given for favoring interpersonal skills over technical abilities was the perception that technical skills are easily acquired, learned, or bought. One person wrote, "Everybody can pick up the technology. Few have the interpersonal skills necessary to work with people and manage operations that affect everyone." Another stated, " You can hire technicians to handle technical issues. The manager needs to be able to interact with everyone who seeks help and to assign tasks and monitor compliance." Another 
comment to this effect included one person who stated that "it is easier to gain technical knowledge by self education. Some never gain the interpersonal skill necessary to teach technology." A fourth respondent wrote, "Technology skills can be learned more easily than interpersonal skills, which are often pretty much set by adulthood."

Some placed great emphasis on actual communication styles and methods of relating to other staff. One person wrote that interpersonal skills trump technical knowledge because "I can know everything about all the equipment, but If I'm ugly to everyone who asks me a question, nobody will ask, even the important questions, and all that money spent on technology will be meaningless." Another asserted that "It's so important to be able to communicate with people and not regress into a confusing jumble of acronyms and strange terms. But, you need to be able to understand the language of computer nerds when you come across them."

Other comments included:

"Given a certain base level of technical skill, interpersonal skills, undoubtedly, as for any manager. Unless the department is tiny, the CIO is more into planning and making choices. His people skills help ensure that his subordinate co-workers are happy little grigs, getting through the work." 
"Interpersonal skills--strong support staff can provide the technology skills, interpersonal skills are critical to conceptualizing and communicating a vision of the role of technology to the early adopters as well as to near Luddites."

"I think when dealing with librarians, who sometimes don't know a network hub from a motherboard, the technical person needs patience when dealing with different departments, different needs, and different levels of use/understanding."

A second group of respondents $(27 \%, n=11)$ placed greater importance on technological abilities. One wrote that "at our institution, technology skills are so limited that I think we need these more." Another stated, "It's hard to manage people when you don't have enough knowledge to gauge what they are doing or direct them in a meaningful way." A third confessed, "I hate to say it but technology wins out. Even if that means I have to put a buffer between a nerd and his staff."

Other comments to this effect included:

"You can always hire them a secretary to take phone calls, but if they don't have the technical chops, you're in trouble."

"Technology skills, because not too many people have them. Interpersonal skills are important to any job but people tend to either have them or not." 
"At the moment, technology because we are still buying hardware and software. There are staff still not trained. Interpersonal skills to come later for encouraging staff to use the system and learn from each other and ask for additional funds and services."

A sizable number of respondents $(27 \%, n=11)$ were ambivalent about this question. They recognize the importance of both types of skills when managing computer resources. They also understand that prioritizing these abilities often depends on the circumstances. One person wrote that the absence of either ability will ultimately lead to unhappy patrons and staff, and therefore both technical and personal skills are critical to the success of Information Technology managers. Another stated, "My most valuable role is in getting the technical people to understand what the librarians need and why, and getting the librarians to understand what is technically possible without overwhelming them with jargon."

Other comments included the following:

"This person needs the technical skills but also needs the interpersonal skills to present/explain information to non-computer oriented folks."

"The manager who has the people who do the former (technical) needs the latter; the manager without the former needs it foremost." 
"Depends on who else is on the team as to which qualities the Information Technology manager would most require."

"Both. The tendency is for them to have the former but no clue about the latter and no idea of customer service or customer focus."

"Both, to work with the staff, patrons and at the same time work with them to build up your computer skills as well as theirs."

"Both! If you're managing people (your most valuable asset), you need more than the technical know how. You need to be able to set expectations and communicate effectively."

\section{Distribution of Computing Resources}

How are computer resources distributed in your organization? Does each department have autonomy over its computer budget, or are all computer expenditures controlled by one individual or department? How does this philosophy of computing resources impact you and your department?

About half of the respondents $(54 \%, n=22)$ described their computing resources expenditures as being centralized and/or "top-down." One person wrote that "final say on branch allocations rests with the executive management team. Decisions are also under 
the review and/or approval of the information technology team. In an operation that has to really pinch pennies, we are coping pretty well with the arrangement." Another said, "All expenditures come from the Computing Department. They will buy only what they want to support. The library is often at odds with this department because we ask them to buy and support things they are not familiar with -- such as Ariel, RealPage, etc. We are willing to pay for it in the library, but we need their support to do it."

The two statements above reflect the differing views of centralized computing financial management. The first statement expresses contentment with this top-down philosophy, insofar as sufficient computer power is continually made available. The second statement elicits concern and even some resentment at being told what they can and cannot purchase. The following comments reflect each of these opposite responses to centralized information technology management:

"Computer resources come down from the top. The top gets the good goods.... Technologically, I'm treated very well, but I fight for everything anyway. That way they can't forget I'm here."

"All computer resources are controlled by a group of unpaid appointed Board of Trustees, some of whom go to educational conferences and come back with strange and exotic ideas that are expensive, impractical, and probably won't work. I find nagging, threats, and whining useful professional tools." 
"Organization is good about providing hardware. However, software and maintenance is tightly controlled by Information Systems which provides horrible service. As a result library workstations are several years behind my home computer. A lot of my work I do at home rather than at work because of inadequate software."

"All computer expenditures are controlled by one department (mine). The computer supplies for all the computers in all the departments come out of my budget. It seems to work okay, because since we support everything, we want to make sure they buy stuff that we can support. No one else would really know how to go about ordering computer stuff, anyway."

"We have a centralized Systems department for our library, which purchases and maintains all hardware and software. We do have the option to purchase equipment from our own departmental funds as well."

"We have a system-wide technology budget (new last year) which my team uses to replace, upgrade and buy new computers. Each department submits a wish list and we allocate by need. The director reviews our recommendations and usually goes along with what we request. I also run the technology task force for the library which meets once a month to discuss all kinds of technology. In this way, if an emergency, non-budgeted need arises, it can be addressed within the year's plan if necessary." 
"Computer expenditures are controlled by a central Information Technology department. Because of the critical nature of computers in the library, Information Technology will usually work with us for what we need/want. This is fine with me."

A few respondents described their computer management model as decentralized (24\%, $\mathrm{n}=10$ ). One wrote, "The computer resources budget (hardware, software, maintenance, automation system, Internet services, dedicated Internet lines) is part of the overall budget for the library and so officially controlled by the director. She solicits input from all departments when developing the budget." Another said, "We have our own budgets, although purchasing of computers is standardized in the organization." A third stated, "Expenditures are controlled by the director, but he is open to suggestion."

For some, decentralization was a positive, important way to empower individual departments (or the library itself in a small organization). As one respondent wrote, "The library has its own computer budget. Our management group usually figures out how to dole that money out to the departments. They're very public services oriented, so my department (reference) ends up with a lot of that money." Another said, "We have our budget, and how we spend it is our affair generally speaking. Expenditure over a certain amount becomes capital expense, and that is a matter of getting permission from a committee for the expense. We have choices, within reason."

A third person who saw decentralized control of computing resources in a positive light wrote, "Control over computing resources are distributed at different levels. Campus 
resources such as Internet connections are distributed to Schools and Colleges who further distribute within their School. Schools and Colleges have budgets for computer equipment, units can supplement their portion of this through campus level grants or departmental budgets. Much software is provided centrally by the School, additional software can be provided through department budgets. This distributed model has allowed me and my department to meet almost all needs of staff and clients."

For others, however, decentralization was a disadvantage in that smaller departments could not see the larger picture and make decisions accordingly. One wrote, "No one person in my department is in charge of computer expenditures, or of knowing who needs what, so consequently everything that happens is very scattered, haphazard, and uncoordinated." Another person stated, "Each department has autonomy over its computer budget, and this doesn't work well in my opinion."

Several respondents drew a picture of information technology resources that are both distributed and centralized $(15 \%, n=6)$. One person wrote, "We have both. We run very much a federalist approach. There is departmental equipment money around campus and then there is central funding for infrastructure. There is oversight and suggested standards and preferred vendors. Support is distributed and located in colleges and departments but coordinated centrally and through a college-level management team."

Other voices from the "both/and" camp include the following: 
"There is a mixture -- we have an automation budget which covers some things, but funding for other computers is centrally managed."

"Yes, no, and maybe. Most major computer expenses come out of the general budget of the college with departments letting administration know their needs in the budget process. After the "big buy" through bidding, then each department can meet ongoing needs through their own budget."

"Expenditures are controlled at the department level but software, hardware and network policies are established centrally."

\section{Personal use of Computers}

Does your organization (or library) maintain a strict distinction between personal use of the Internet (or computers in general) and business use?

Somewhat more than half of the respondents $(59 \%, \mathrm{n}=24)$ stated that personal use was allowable under the policies of their organization, while the rest $(41 \%, n=17)$ said that it was not permitted. Many underscored the fact that the policies that do exist tend to be ambiguous and allow for some flexibility. 
Those respondents who described their institutional policy as prohibiting personal use wrote the following comments:

"This issue came before our Board of Directors. Specifically, should employees be able to sign the organization's name to political emails. There was concern this might shed a poor light on the organization that might affect our future federal funding."

"We have an email policy and a network use policy that addresses these issues."

"We do not allow WWW access for recreational or personal use."

"We try to discourage personal use of the Internet on library time, but it's difficult to enforce."

"Fairly strict, although there is a subtle recognition that the receipt of the odd personal email message is not a problem."

"Browsing is allowed on breaks, lunch and after hours."

"The library encourages all sorts of computer use except chatting and game playing."

Respondents to the survey whose institutions did not have policies restricting personal use of the Internet made the following remarks: 
"Not specifically. No formal policy exists on this issue. But it is generally understood that personal use is OK provided it is done outside working hours and does not violate other policies in regards to appropriate behavior."

"Very loose distinction, because not that many employees are comfortable with computers, so anything that can keep their interest and increase computer use is encouraged."

"No, even though it is clear that some state agencies are not as fortunate. There has been some discussion about this at the university level on many campuses. Academic tradition has made this territory one in which I am certainly not interested in treading."

"We encourage staff to make personal use of our technology in their own time. This has led to a more aware staff and has resulted in greater efficiencies in use of technology."

"We're fairly loose about this, but we can trust our staff not to abuse the computers. We don't have enough for everyone to have their own, so because they share, it's hard to go crazy anyway."

\section{Computer Usage Problems}


Have you or other staff in your organization experienced problems (physical or otherwise) in using computers? I'm thinking here of such common problems as eyestrain, carpal tunnel syndrome, computer phobia/avoidance, etc.

Most respondents $(73 \%, \mathrm{n}=30)$ agreed that computers generate a variety of physical problems in the workplace, the most common being carpal tunnel syndrome. One person stated that "a disabilities insurance carrier dropped our coverage because of such widespread carpal tunnel type claims." Another respondent wrote, "I have had to train my non-dominant hand to use the mouse as my other hand was getting pretty weak and got sore easily."

Others reported physical problems included back pain, eyestrain, and headaches. What causes these problems? One person implied that it was furniture when he/she wrote, "Our institution is a little on the cheap side when it comes to furniture for staff." Another blamed her physical problems (especially her sore back) on "poorly designed chairs." Others blamed the repetitious use of the mouse and/or the computer keyboard, or simply sitting too long in one position.

But what is being done about these issues? Some respondents simply "work around [their] problems" by getting new eyeglasses or new furniture. Others "hope for some good developments in input technologies, such as voice, other kinds of pointing devices, etc." One respondent noted that "we have begun a Safety and Wellness Committee and now spend thousands of dollars a year outfitting everyone who needs it with 
ergonomically designed workstations. The organization has a budget for ergonomic and stretching consultations and seminars with local experts." Another wrote, "We have been particularly attuned to ergonomics as we have moved people into intensive keyboard activities. Have even included articles in memos on the subject and have had workshops." A third respondent said that "no-wrist guards are used liberally. Staff are encouraged to take breaks from using the computer and support for computer use and training is a high priority." Others report the use of "mouse mitts" and efforts at becoming "ergonomically conscious."

"I think they are beginning to see more and more," stated one respondent. "We are at the tip of the iceberg [regarding physical computer-related ailments]." Another summed up the comments of many of these respondents when she wrote, "I'm quite concerned about the state of my wrists -- with 30+ years ahead of me in the work force. Fortunately, my day is usually varied physically so that I'm not chained to a workstation eight hours a day."

While physical problems are quite troublesome for many library staff, psychological issues seem to cause almost the same level of concern. Computer phobia and computer avoidance are two related "disorders" that appeared frequently among the answered surveys. One respondent stated that she sees "computer phobia every day in new users and one old user who just panics [when using computers]." Another wrote, "I think we see phobia as simply being people who just are never comfortable with the logic of a computer." Describing computer anxiety, one person opined that "this state of affairs is 
not improving," and another wrote that computer anxiety creates discomfort for many beginning users and makes for a "difficult learning process."

Almost all of the responses to this question referred to computer phobia or avoidance on the part of beginning end users or inexperienced staff. However, one person confessed that he experiences a kind of computer avoidance that may be more prevalent among information specialists than we are often apt to admit. This respondent wrote, "I work on the computer so much at work, that when I get home I cannot bear to touch my own."

Avoidance of computers seems to be related to computer phobia. One respondent wrote that "many users experience sheer confusion at the complicated nature of the Web and searching it (leading to major avoidance)." Others agreed that the self-imposed solution for many anxious computer users is avoidance of computer-related tasks. But one person offered that while "computer phobia is possible, avoidance is not an option," given the ubiquitous nature of computers in almost any kind of organization.

One possible solution proposed for computer anxiety relief is to "give [the anxious person] something new, then take it away .... It makes the old computer things she knows seem easy and she doesn't panic overly much." Another respondent stated that "there are always one or two in an organization who don't trust the computer and who spend much time duplicating tasks done by machine. We just let them "bonk" around." Perhaps the most reasonable solution proposed came from one librarian who wrote that "continued exposure" to computer use has helped ease anxiety in most cases. 


\section{Should Libraries be on the Cutting Edge}

Do you think that libraries (or other information-based organizations) should be on the "cutting edge" or the "trailing edge" in terms of computing resources? Why?

This question elicited strong responses from both sides of the aisle. A significant number (44\%, $\mathrm{n}=18$ ) answered that library and other information-based organizations should definitely be on the cutting edge of computing resources. One person wrote, "Ideally, on the cutting edge. Practically and hopefully, near the front of the pack. We can't really afford to be bringing up the rear if we want to be in business in the not too distant future." Another stated, "Closer to cutting edge because we are the place where most people without computers come to access the Internet. Poor technology can turn off most patrons, particularly if they are just getting their feet wet in the Net."

Some of the responses were absolute and forceful in their advocacy of cutting edge computing. One person stated, "We should be striving to be at the cutting edge both for our staff and for our patrons. Staff should have access to state of the art hardware, software and local and remote information resources in order to give the best possible service to patrons. The library also has an obligation to provide these resources for patrons who cannot gain access in any other way." Another respondent wrote, "Of course on the "cutting edge" because people look to us to be the information experts. In today's 
age, information experts and computing resources go together hand in hand." Others wrote that being on the cutting edge "will bring more people into the library and give it more reason for being," and that having the most up to date computer equipment and applications sets "an example of professionalism."

Some of the answers were couched in triumphalistic language. For example, one person stated that cutting edge is clearly the only choice because "we are the information people and computers access the Internet and the information age." Another wrote, "Cutting edge -- of course. We can't do our job of providing timely accurate information unless we are given the resources." A third asked the question, "Why would anyone want to be on the trailing edge? I do not understand how this could even be suggested."

Other reasons given for wanting to be at the forefront of technology include the following:

"Cutting edge, to be able to help the public in their learning and use of these resources."

"Cutting edge. I believe this is the great opportunity for librarians. The greatest skills needed in the information age are organizational skills which is the heart of librarianship."

"Libraries should be as far to the forefront as they can manage in order to keep the patrons coming in to use the resources." 
"Cutting edge... and I think that we have been. Seems to me on our campus we were the first to have a LAN, to provide workstations for students to use electronic resources, to see the benefits and pitfalls of the Internet. We embraced email and listservs long before our faculty did. We, in the library, have the evaluation and research skills to identify useful technology and we have had the budget constraints to teach us to get the best for the best price and get what is determined to be useful. We don't waste much around here."

"I believe that libraries, as community access points, are well placed to showcase cutting edge technology where it could positively impact on the libraries' functions. Of course, it depends on what we're talking about... a robotic tape changer with a capacity of 2 terabytes might be cutting edge, but certainly not something most libraries would need. A new browser that greatly simplified searching the Web might also be cutting edge and libraries would certainly want to be in that one."

"Cutting edge, training the current generation of information seekers how to find what they want in a decent time frame."

Several respondents agreed that libraries should be at the technological forefront but felt that this statement deserved a qualification or a caveat in one form or another. For example, the idealistic vision and the mundane reality are often far apart, in the opinion of many librarians. One person wrote that "libraries "should be 'cutting' but in practice 
are often 'trailing'--though some consolidation is needed before librarians can commit themselves to new technologies." Another wrote that libraries "should be on the cutting edge but they never are."

Another qualification that was made by several respondents was the barrier of funding. One person stated, "They should be on the cutting edge, but it is not likely to happen because of funding issues in hospitals, academic, school, public libraries." Another said, "Cutting edge in as far as the budget goes." A third wrote, with not a little rancor in his tone, "Which libraries? Many academic libraries are (or think they are) cutting edge, and deserving of great salaries. Many of us in public libraries are often just trying to get the doors open each morning. Let the guys with the big budgets be cutting edge."

A slight majority of respondents $(51 \%, n=21)$ stated that cutting edge technology should be pursued but also limited by the size of the library, available time, available training, and need. These respondents reflected ambivalence in their answers in that neither the cutting edge nor the trailing edge were deemed appropriate for libraries. This viewpoint might be called the qualified cutting edge or the "all things in moderation" perspective. One respondent wrote, "I believe that we should be on the "cutting edge" but certainly there are limitations in terms of time and available training. I also believe that there are many things going on in technology that I will never need to know and I don't want to have to know them." Another respondent wrote, "We need to be paying attention to what is coming down the road. When we provide the information for them, we need the best equipment we can have -- T1s, Pentium IIs, whatever. Within our library space, both 
public and office, we need to be keeping up at least. (It's like buying the first year of a new model car; it's better to wait until the bugs are out, so I guess I don't believe in strictly cutting edge. We can't afford to make mistakes in a public library.) However, most of our patrons do not have DVD players, run 386s over telephone lines, don't know how to use a mouse, have never seen the Internet. So we need to be "backwardsly" compatible when they access our system. So maybe there are two standards. If we are the end user, give us the best we can afford; if the patrons are the end user, aim for the most common level of equipment and knowledge."

One respondent said, "Middle-of-the-road. Cutting edge leaves too many people out. Trailing edge doesn't provide service as good as it can be and also creates an image of us as having no technical saavy." Another wrote, "Perhaps in the middle. Let other folks work out the major bugs but then librarians should become a part of design/implementation of computing technologies." A third stated, "Neither. While experimentation needs to be encouraged and rewarded and occasional failure to be understood, one can't be too far ahead of the curve before one knows where the curve is located. There is plenty of room to experiment within existing bounds with known technology being used in specific applications." Still another wrote, "We need to strike a balance. The constraints of our budgets means that we need to show appropriate caution in pursuing the cutting edge. However, if we are always or often at the trailing edge, we risk being marginalized by those who look at technology as the answer, not as the tool for meeting client needs." Other similar statements included the following: 
"I think libraries should be one half step behind the cutting edge - it's not called the "bleeding" edge for nothing. Libraries, especially those in the public sector, have a responsibility to spend their money wisely, and I believe they should be somewhat cautious about embracing new and unproven technologies. Libraries also have a role in advocating for less-well-off users and must remember those individuals in making technology plans."

"I think we should be on the trailing edge with most technology. We do want to be on the cutting edge with library automation software, though."

"I am satisfied if I can be in the middle. No use wasting money on a dead end. Don't want to wait to trail."

"Not necessary to be on the cutting-edge. No point having technology that few understand/can use, but not trailing edge either. Better to be somewhere in between, where people are reasonably comfortable or at least familiar with the technology."

"Cutting edge certainly sounds good, but probably isn't always necessary for smaller organizations. Also, please make sure things work before you give it to me -- cutting edge hasn't necessarily had the bugs worked out of it."

The above statements reveal the caution with which many librarians approach the issue of user-computer comfort levels. Steep learning curves for new technology will make many 
librarians back away because it implies longer training sessions and greater levels of user frustration.

Another reason given for this compromise solution was financial constraints. One wrote, "It's expensive to be on the cutting edge, but we can't afford to be on the trailing edge either." Another said, "Somewhere in the middle. Libraries can't afford to be cutting edge, but don't need to be last in the race either." A third wrote, "We traditionally don't have a whole lot of money or resources, so it'd be nice to let big business make all the mistakes with new technology and then step in and learn from their mistakes."

\section{ANALYSIS}

While no clear majority emerged from the question about managerial skill sets, the largest number of responses came from those who believed that interpersonal skills were more important than technical skills. This may reflect a belief by librarians that the ability to communicate is closer to the heart of our profession than a knowledge of technology. Or, it may reveal a stereotype (that is all too often played out in real life) of the computer guru as a socially awkward nerd. However, the number of respondents who answered that technical skills were more important than interpersonal skills demonstrates that a sizable minority of librarians believe that technical competence among library managers is a very important trait. Delegation without knowledge is seen as a form of abdication and a prescription for chaos. 
This question was posed in an "either/or" fashion. Respondents were asked to choose either technical skills or interpersonal skills as the more important characteristic of library managers. Replying that both skills were equally important was not listed as an optional response. Yet, a relatively large number of respondents (27\%) chose this path. These answers may suggest ambivalence among librarians today regarding managerial skill sets. Refusing to make a choice between the two alternatives and instead opting for the "both/and" route may indicate a desire to "have it both ways" and hire well-rounded, capable individuals for library management positions. Or, it may simply mirror actual job requirements for technology managers, where both sets of skills are seen as crucial to the success of the position.

In response to the question about the distribution of computing resources in libraries today, more than half of the respondents described their organizations as centralized or "top-down." This is undoubtedly simply an accurate description of modern bureaucracies, although it may point to a lack of flexibility and collaborative thinking among library and computer administrators. What is more interesting is the presence of conflict in many of the answers to this question by those in centralized organizations. For example, some of the phrases used include the following: "the library is often at odds with this department;" "I fight for everything;" and "I find nagging, threats, and whining useful professional tools." These words indicate a certain amount of anger and helplessness among many librarians and library managers who feel disempowered by the technological administrative infrastructure. 
By contrast, the smaller number of respondents who described their computer management model as decentralized often used words that connoted a feeling of empowerment and satisfaction. As one respondent wrote, "This distributed model has allowed me and my department to meet almost all needs of staff and clients." However, decentralization was a definite disadvantage to some respondents, due to the perception (real or imagined) that distributed administrative structures promote "scattered, haphazard, and uncoordinated" environments. These two conflicting perspectives demonstrate that no matter how attractive a management model looks in theory, it simply will not work well in some organizations due to personality conflict, abuse of power, or incompetent managers.

The third question dealt with personal use (by staff) of business computers in library settings. A majority of respondents (59\%) stated that personal use was permitted under the rules of their organization. These respondents included those whose organizations did not address this issue at the policy level as well as those whose organizations set forth somewhat ambiguous or flexible rules about computer use. This may reflect the flexible and somewhat informal working environment of many libraries, or it may simply indicate that libraries, along with many other kinds of organizations in the modern world, find policing the computer usage habits of staff to be quite difficult and sometimes even counterproductive to a positive working environment. 
The next question addressed computer usage problems in libraries. A super majority (73\%) agreed that computers cause a variety of physical and psychological problems in the workplace. While the most common ailment mentioned was carpal tunnel syndrome, other maladies were also discussed, including back pain, eyestrain, headaches, and computer anxiety. Library managers are sympathetic to these issues and provide a variety of solutions for many of these problems, such as ergonomically correct furniture, in-house training, and "no-wrist guards." However, the psychologically-based ailments, such as computer phobia and computer avoidance, do not seem to generate the same kind of empathy among library managers and computer-savvy librarians. This may be due to a mindset among some managers that psychological problems are somehow less "real" than physical symptoms, and that "continued exposure" to computers will solve most of these kinds of afflictions. In any event, the large number of respondents acknowledging computer-generated disorders must surely be a cause for concern for library managers.

The final question asked if libraries should be on the cutting edge or the trailing edge in terms of computer resources. The respondents were divided between those who believed that libraries should be on the cutting edge and those who asserted that libraries must find the balance between new technology and other factors such as the size of the library, available time, budget, training resources, and need. This second perspective, which I call the "qualified cutting edge," was held by a razor-thin majority (51\%) of the respondents. This reflects the growing chasm today between those library managers who advocate unqualified enthusiasm (sometimes approaching a messianic fervor) toward information technology, and those who caution moderation and a "wait and see" attitude. 
While many librarians try to hold the middle ground (as this survey indicates), others are polarized and resentful of those on the opposite end of the spectrum.

\section{CONCLUSION}

A variety of themes and patterns has emerged from this survey. Managers of computing resources are viewed as requiring both interpersonal skills as well as technical abilities. Distribution of computing resources in libraries is diverse and complex, but most libraries continue to mirror the "top-down" mentality of the modern, centralized bureaucracy. Libraries tend not to highly regulate personal use of computers by staff, but instead maintain (for the most part) a flexible approach to this issue. Computer usage problems, both physical and psychological, are common in libraries. Librarians and library managers are spread across the spectrum of opinion in terms of the extent to which technology should be utilized in libraries. Some are strong advocates for cutting edge technology, others hold a more moderate position, and some are cautionary and somewhat distrustful of using cutting edge technology in libraries.

Given the findings of this article, it is clear that libraries and library managers must prepare for the future in numerous ways. Managers must continue to develop skills in interpersonal relations and communication, as well as in technical areas. While some libraries may require (for various reasons) a rigid, centralized management structure visà-vis computing resources, others will benefit from the movement toward a more flexible, 
decentralized administrative model. Likewise, flexibility in determining staff policies for personal computing will engender a more healthy, trusting environment in most organizations. Library managers must address the issue of computer usage problems among staff. Healthy employees are crucial for the success of any organization, and managers should seek remedies for the technological ills, both physical and psychological, which plague modern libraries. Finally, library managers should seek a balance between the overly ambitious approach to technology and the overly pessimistic perspective. Polarization in either direction will result in resentment and a decline in productivity among staff.

Future research should continue to focus on the issues addressed in this article. Can management skills in information technology somehow be quantified? Does decentralization of computing resources correlate with greater efficiency and productivity, or should managers maintain strict, "top-down" control over technology? How do academic library policies on the personal use of computers by staff compare with those of public libraries or special libraries? Can data be gathered that would measure the negative effects of computer usage problems on staff productivity? Can a managerial philosophy of leading edge computing be correlated with budget expenditures or workplace productivity? These and other related questions could be answered with more precision and scientific accuracy through the use of quantitative, statistically reliable methods. 


\section{REFERENCES}

Farrow, J. (1997), "Management of change: technological developments and human resource issues in the information sector," Journal of Managerial Psychology, Vol. 12 No. 5, pp. 319-324.

Foster, C.D., and Bell, S.J. (1998), "The agile technology manager: adapting new technologies to connect people with information." In Haricombe, L.J. and Lusher, T.J. (Eds.), Creating the Agile Library: A Management Guide for Librarians, Greenwood Press, Westport, Connecticut, pp. 45-59.

Gorman, M. (1997), "Living and dying with information," Library Trends, Vol. 46 No. 1, pp. 28-35.

Hudson, M.P. (1999), "Conflict and stress in times of change," Library Management, Vol. 20, No. 1, pp. 35-38.

Lancaster, F.W., and Sandore, B. (1997), Technology and Management in Library and Information Services, University of Illinois Graduate School of Library and Information Science, Champaign, Illinois.

Lowry, C.B. (1993), "Managing technology," Journal of Academic Librarianship, Vol. 19 No. 4, pp. 237-239. 
Martin, M.C. (1999), "Managing your library's computer nerds," Computers in Libraries, Vol. 19 No. 2, pp. 8.

Riggs, D.E. (1999), "Library management and technology," College \& Research Libraries, Vol. 60 No. 6, pp. 512-513.

\section{ENDNOTE}

1. The survey may be found in its entirety in the author's Leading the Wired Organization: The Information Professional's Guide to Managing Technological Change, Neal-Schuman Publishers, 1999.

\section{APPENDIX}

\section{Managerial Skill Sets}

What do you think is more important for a manager of computer resources: technology skills or interpersonal skills? Why? 


\section{Distribution of Computing Resources}

How are computer resources distributed in your organization? Does each department have autonomy over its computer budget, or are all computer expenditures controlled by one individual or department? How does this philosophy of computing resources impact you and your department?

\section{Personal use of Computers}

Does your organization (or library) maintain a strict distinction between personal use of the Internet (or computers in general) and business use?

\section{Computer Usage Problems}

Have you or other staff in your organization experienced problems (physical or otherwise) in using computers? I'm thinking here of such common problems as eyestrain, carpal tunnel syndrome, computer phobia/avoidance, etc.

\section{Should Libraries be on the Cutting Edge}

Do you think that libraries (or other information-based organizations) should be on the "cutting edge" or the "trailing edge" in terms of computing resources? Why? 